\title{
Ressignificação da vida do cuidador do paciente idoso com câncer
}

\author{
Ressignification of life of caregivers of elderly patients with cancer \\ Ressignificación de la vida de los cuidadores de pacientes de edad avanzada con cáncer
}

\author{
Anna Cláudia Yokoyama dos Anjos', Márcia Maria Fontão Zago' \\ 'Universidade de São Paulo, Escola de Enfermagem, \\ Programa de Pós-Graduação em Enfermagem Fundamental. Ribeirão Preto-SP, Brasil.
}

Submissão: 04-02-2013 Aprovação: 27-08-2014

RESUMO

O estudo objetivou analisar o processo de tornar-se cuidador de idoso com câncer, submetido à quimioterapia, no contexto domiciliar. Estudo exploratório, com orientação teórico-metodológica da antropologia interpretativa e estudo de caso etnográfico. Os dados foram coletados de janeiro a setembro de 2009, com quatro cuidadores, por entrevistas semiestruturadas, observação e consulta em prontuários. Com a análise dos dados foram construídas quatro unidades de significação. Apresentamos neste artigo a unidade temática "A ressignificação da vida do cuidador", composta por aspectos positivos da atividade de cuidar e de ajudar a superar dificuldades, como união, solidariedade, oportunidade de reaproximação. As dificuldades foram mais evidentes, principalmente pelo despreparo para cuidar em domicílio, que levou a transformações nas relações familiares e sociais do cuidador, resultando em comprometimento dos aspectos físicos, emocionais e sociais. O enfermeiro, como agente do cuidar, deve prover qualificação adequada ao cuidador, auxiliando-o no enfrentamento da doença e na melhoria da relação cuidador-paciente-serviço.

Descritores: Família; Idoso; Cultura; Enfermagem Oncológica; Pesquisa Qualitativa.

\begin{abstract}
The study aimed to analyze the process of becoming a caregiver of elderly patients with cancer, in chemotherapy, in the home context. This is an exploratory study with theoretical and methodological orientation of interpretative anthropology and ethnographic case study. Data were collected from January to September 2009, with four caregivers through semi-structured interviews, observation and consultation records. With data analysis were built four units of meaning. In this paper we are focusing the thematic unity "The ressignification of caregiver's life", composed by positive aspects of caregiving activities and of helping to overcome difficulties, such as union, solidarity, opportunity for reapproximation. The difficulties were more evident, especially being unprepared to care at home, which led to changes in the caregiver's familiar and social relationships, resulting in impairment of physical, emotional and social aspects. The nurse, as an agent of care, must provide adequate qualification to the caregivers, helping them in coping with the disease and improving the patient-caregiver-service relationship.
\end{abstract}

Key words: Family; Aged; Culture; Nursing Oncology; Qualitative Research.

\section{RESUMÉN}

El estudio objetivó analizar el proceso de convertirse en cuidador de pacientes de edad avanzada con cáncer, que reciben quimioterapia, en el contexto del hogar. Estudio exploratorio, con orientación teórica y metodológica de la antropología interpretativa y del estudio de caso etnográfico. Los datos fueron recogidos entre enero y septiembre de 2009, con cuatro cuidadores, por medio de entrevistas semi-estructuradas, observación y consulta a los prontuarios. Con el análisis de los datos se construyeron cuatro unidades de significado. Aquí está presentada la unidad temática "La ressignificación de la vida de los cuidadores", consistiendo de los aspectos positivos de las actividades de cuidar y de ayudar a superar dificultades como la unión, la solidaridad, la oportunidad de acercamiento. Las dificultades eran evidentes, sobre todo para los cuidadores no preparados para el cuidado en el hogar, lo que llevó a los cambios en las relaciones familiares y sociales del cuidador, resultando en el deterioro de los aspectos físicos, emocionales y sociales. La enfermera, como un agente de la atención, debe proporcionar la cualificación adecuada al cuidador, ayudando-o a hacer frente a la enfermedad y a mejorar la relación paciente-servicio-cuidador.

Palabras clave: Familia; Anciano; Cultura; Enfermería Oncológica; Investigación Cualitativa.

\section{AUTOR CORRESPONDENTE Anna Cláudia Yokoyama Anjos}

E-mail: annaclaudia1971@gmail.com 


\section{INTRODUÇÃO}

A elevada incidência de doenças crônico-degenerativas na população de idosos é característica da transição epidemiológica mundial desde o último século(1). Dentre as de maior prevalência entre os idosos, destaca-se o câncer. Atualmente esta população tem sido alvo de preocupação dos governos que, por meio de políticas de saúde específicas, consideram o processo da senescência e a senilidade gerador muitas vezes de condições de extrema fragilidade, requerendo tratamentos e internações freqüentes, de altos custos e ainda, mobilizando grande número de pessoas da família, do convívio social, além dos próprios serviços e profissionais de saúde ${ }^{(2)}$.

Considerando a porcentagem de pacientes diagnosticados tardiamente e a disponibilidade de tratamentos para casos avançados, observa-se que grande parte desses idosos é submetida à terapêutica quimioterápica, como uma das modalidades de terapia. A quimioterapia utiliza medicamentos que trazem ao paciente uma série de alterações físicas, efeitos colaterais e reações adversas de difícil controle e manejo, principalmente nos dias subseqüentes à infusão das drogas. São efeitos indesejáveis, temidos pelos pacientes, que demandam uma série de cuidados domiciliares, visto que o tratamento geralmente é realizado no ambiente ambulatorial, devendo o paciente retornar ao domicílio após cada aplicação.

Em geral, os cuidados ao paciente em quimioterapia são executados por familiares ou pessoas próximas, no próprio ambiente domiciliar. O domicílio e a família são considerados como local e sistema ideais, respectivamente, para que experiências sejam bem sucedidas, dados os próprios valores culturais neles presentes ${ }^{(3)}$. Observa-se que a Política de Atenção ao Idoso tem incentivado esta prática, por considerar o lar e a proximidade da família como melhor opção, garantindo a autonomia, preservando a dignidade e a integridade do indivíduo adoecido(4). Ressalva deve ser feita quanto a este apontamento, uma vez que nem todo domicílio e/ou família possui estas características.

Contudo, a família nem sempre tem a capacidade de organizar-se para o cuidado do idoso e, por isso, a pessoa mais próxima, ou que tenha maior disponibilidade, assume o cuidado integralmente, sem estar suficientemente capacitado, o que pode repercutir em consequências desfavoráveis à vida do cuidador ${ }^{(1,5-6)}$. Atualmente, as mudanças estruturais familiares têm mostrado escassez de pessoas para assumir o papel de cuidador, o que resulta em sobrecarga de um membro. Esta nova conformação familiar pode ainda ser geradora de dificuldades financeiras, pois, pelo número reduzido de pessoas, passa a ser necessário contratar alguém para exercer o papel de cuidador e a família passa a despender de recursos financeiros para cuidar de seu idoso adoecido(3).

Conhecer o contexto domiciliar de cuidadores de pacientes com câncer, submetidos à quimioterapia, e especificamente de pacientes idosos, nos inquietou durante muito tempo pois, convivemos com este grupo apenas no serviço de saúde. As particularidades do contexto onde pacientes convivem com sua família, a relação com a comunidade e as influências da cultura, nos diferentes modos de agir, eram aspectos desconhecidos das pesquisadoras. Perguntas surgiam, principalmente sobre como enfrentavam os problemas decorrentes do tratamento, quando estavam em seus lares, sem a assistência e amparo da equipe de saúde.

Pouco se tem encontrado na produção científica brasileira sobre o cuidador do idoso com câncer e, especificamente aquele submetido à quimioterapia, nada foi observado. Em recente publicação, onde foi realizada uma revisão integrativa abordando os estudos nacionais relacionados aos cuidadores de idosos, nenhum estudo foi incluído que abordasse o cuidado do idoso com câncer ${ }^{(2)}$.

Vislumbramos o cuidado de pessoas idosas no domicílio como desafio real do presente século para as equipes de saúde e mais especificamente para a Enfermagem ${ }^{(1)}$, que deve desenvolver habilidades e competências para articular as diferenças e igualdades culturais, transcendendo assim os aspectos puramente biológicos do cuidado ao adoecido pelo câncer, destacando a importância do cuidador familiar e as influências da atividade de cuidador sobre sua própria vida ${ }^{(1,4)}$.

Após exposição do contexto em que se insere o estudo, traçamos como objetivo apresentar, neste artigo, a ressignificação da vida do cuidador do idoso com câncer submetido à quimioterapia, extraída de um estudo mais amplo, que teve a finalidade de analisar os sentidos atribuídos à experiência de ser cuidador do idoso com câncer na terapêutica.

\section{PERCURSO METODOLÓGICO}

Estudo exploratório, com orientação teórico-metodológica da antropologia interpretativa e estratégia de estudo de caso etnográfico. A abordagem metodológica interpretativa é justificada pelo nosso interesse em identificar e analisar as subjetividades do processo em foco, de modo compreensivo e contextualizado. A antropologia interpretativa forneceu-nos a base teórica para interpretação dos dados, pelo foco na cultura como sistema simbólico, que é empregada pelas pessoas para dar sentido à doença e ao cuidar ${ }^{(7)}$.

Imbuídos da necessidade de compreensão do processo de tornar-se cuidador do idoso com câncer submetido à quimioterapia, foi utilizada a etnografia como método de investigação antropológica que é tradicionalmente eleita pela antropologia ${ }^{(7-8)}$.

Buscamos conhecer a complexidade do processo para obter múltiplas perspectivas, por meio da estratégia do estudo de caso (EC) etnográfico instrumental, onde foram examinados casos de familiares de pacientes idosos com câncer, submetidos à quimioterapia. Na etnografia, o objetivo do EC é registrar o comportamento humano em termos culturais, estudando o fenômeno em profundidade ${ }^{(9)}$. Utilizamos ainda o genograma e o ecomapa para cada uma das cuidadoras buscando melhor compreensão do contexto familiar e suas relações com as redes de suporte social formal e informal ${ }^{(10)}$.

O projeto foi submetido ao Comitê de Ética em Pesquisa da Universidade Federal do Triângulo Mineiro (UFTM), e foi aprovado em 05/12/2008 sob protocolo $\mathrm{n}^{0} 1220$.

Os critérios de inclusão estabelecidos para participação neste estudo foram: cuidadores/familiares maiores de 18 anos, de 
idosos (paciente com idade superior aos 60 anos) com qualquer tipo de câncer, em tratamento quimioterápico ambulatorial; estar envolvido no cuidado direto e residindo no mesmo domicílio que o idoso; que se dispusesse a participar do estudo, assinando previamente o Termo de Consentimento Livre e Esclarecido (TCLE), para atuar como participante da pesquisa.

A seleção das cuidadoras não obedeceu a nenhum critério de inclusão quanto ao gênero e grau de parentesco; a seleção ocorreu mediante o contato inicial com os pacientes idosos, que estavam em tratamento quimioterápico. Posteriormente fizemos o contato com as cuidadoras para o convite à participação na pesquisa. Utilizamos pseudônimos para nomear as cuidadoras e assim, garantir o anonimato; a saber: Jô, Ana, Sara e Maria. As cuidadoras foram orientadas e esclarecidas quanto aos objetivos da pesquisa, forma de participação e autonomia individual, assim como em relação a privacidade e confidencialidade das informações, além da finalidade científica.

Os dados foram coletados no período de janeiro a setembro de 2009, por meio de entrevistas semiestruturadas, observação simples do contexto e consulta de fontes documentais. Para o registro das impressões do pesquisador utilizamos o diário de campo.

$\mathrm{Na}$ observação focalizamos aspectos relacionados aos idosos e seus familiares. Nos domicílios, a observação comtemplava a estrutura física da residência, os comportamentos das pessoas e as expressões das cuidadoras junto ao idoso; nos setores de quimioterapia observamos estrutura física e funcionamento dos setores de quimioterapia, hotelaria, materiais, composição e atuação da equipe de enfermagem, bem como o binômio cuidador-paciente; após a observação as impressões da pesquisadora foram registradas no diário de campo.

As entrevistas foram realizadas nos domicílios das cuidadoras e também no serviço de saúde, sendo gravadas e transcritas integralmente. Ocorreram em intervalos iguais ou menores que a periodicidade dos ciclos de quimioterapia recebidos pelos idosos. Utilizamos como perguntas norteadoras as seguintes questões: Porque você assumiu o cuidado do seu familiar? Que cuidados são priorizados? Que tipo de informações/orientações você recebeu sobre a quimioterapia? Fale como é para você conviver com o seu familiar com câncer? Como você se sente em cuidar de seu familiar?

Acompanhamos as cuidadoras durante o tratamento quimioterápico dos idosos, com número de visitas domiciliares, entrevistas e consultas de enfermagem variadas. Foram realizadas 16 entrevistas no total, com as cuidadoras, acompanhadas pelas anotações no diário de campo.

A análise temática indutiva dos dados obtidos foi realizada em etapas (familiarização com os dados, criação de códigos, busca por temas, revisão dos temas, definição de temas e produção final da análise). As unidades de sentido desenvolvidas foram: a opção de ser cuidadora, o cuidado necessário ao idoso, a ressignificação da vida do cuidador. Como referido anteriormente, passaremos a apresentar a última unidade como foco deste artigo.

\section{RESULTADOS E DISCUSSÃO}

\section{Caracterização das cuidadoras}

\begin{tabular}{|c|c|c|c|c|c|c|}
\hline Cuidadora & Idade & Escolaridade & Estado civil & Religião & $\begin{array}{c}\text { Parentesco } \\
\text { com idoso }\end{array}$ & Renda \\
\hline Jô & 75 & $\begin{array}{c}\text { Fundamental } \\
\text { completo }\end{array}$ & Casada & evangélica & esposa & $\begin{array}{c}1 \text { salário } \\
\text { mínimo }\end{array}$ \\
\hline Ana & 73 & $\begin{array}{c}\text { Fundamental } \\
\text { incompleto }\end{array}$ & amasiada & evangélica & esposa & $\begin{array}{c}1 \text { salário } \\
\text { mínimo }\end{array}$ \\
\hline Maria & 27 & $\begin{array}{c}\text { Superior } \\
\text { completo }\end{array}$ & Casada & católica & Filha & Sem renda \\
\hline Sara & 48 & $\begin{array}{c}\text { Ensino médio } \\
\text { completo }\end{array}$ & divorciada & evangélica & Filha & $\begin{array}{c}1 \text { salário } \\
\text { mínimo }\end{array}$ \\
\hline
\end{tabular}

As participantes do estudo tinham como características: todas eram mulheres, cuidadoras de idosos, sendo estes cadastrados para o tratamento quimioterápico em modalidade ambulatorial, em instituições integrantes do Sistema Único de Saúde (SUS). Duas eram casadas (Jô, esposa de Jacó e Maria, esposa de Juliano); uma amasiada (Ana, amásia de Nenê) e outra divorciada (Sara, filha de Maria); três possuíam filhos (Jô, Ana e Sara). A faixa etária variou de 27 a 75 anos, sendo que duas já possuíam mais de 60 anos (Jô e Ana).

Em relação ao grau de parentesco, nossos resultados também corroboraram com a literatura onde a prevalência é de esposas cuidadoras, seguidas das filhas. Conforme exposto em estudo brasileiro ${ }^{(1,11)}$, os cuidados prestados no domicílio são realizados por cônjuges e filhas, o que remete às mulheres, o papel de "grandes cuidadoras", a quem foi atribuído esse papel cultural e social ao cuidar dos filhos, marido e familiares. Na sociedade brasileira a esposa é, com freqüência, a cuidadora primária de idosos, seguida de filhas ${ }^{(1,11)}$.

Quanto à atividade profissional, as cuidadoras tiveram dificuldades em conciliar o trabalho fora de casa com a atividade de cuidador domiciliar sendo necessário, abandonar ou reduzir a jornada de trabalho ${ }^{(12)}$. Neste estudo, apenas uma das cuidadoras trabalhava fora de casa. Sobre a renda financeira percebemos que as cuidadoras, assim como os idosos de quem cuidavam, tinham baixa renda, em geral proveniente de aposentadoria ou do próprio trabalho, não recebiam auxílio financeiro de parentes ou qualquer recurso da comunidade. As condições socioeconômicas, as restrições de acesso a bens materiais e também a serviços, e os bairros de periferia urbana em que residiam caracterizaram as cuidadoras deste estudo como provenientes da classe popular. 
Verificando a opção religiosa, três cuidadoras eram evangélicas (Jô, Ana e Sara) e uma católica (Maria). Hoje há uma diversidade de religiões, seitas e crenças, sendo difícil apresentarmos dados fiéis diante desta grande variedade de opções; no Brasil a religião que prevalece é a católica ${ }^{(13)}$. Observamos uma diferença no perfil das participantes de nossa pesquisa em relação aos dados apresentados por esta fonte, visto que três de nossas participantes eram evangélicas e apenas uma católica.

No que se refere ao tempo em exerciam o papel de cuidadoras, três possuíam entre 2-4 meses; apenas uma exercia esta atividade há mais de cinco anos (Jô). A inserção da família no cuidado do idoso, em geral, teve início anterior ao tratamento quimioterápico. Das quatro famílias, três já possuíam os idosos vivendo em companhia das cuidadoras, o que tornou compreensível que alguém do próprio convívio domiciliar se tornasse a principal cuidadora.

As esposas Jô e Ana, mesmo antes do adoecimento de seus maridos, já realizavam os cuidados domésticos e, sendo aposentadas com baixa renda financeira, não possuíam condições de contratar ajuda externa remunerada. Ao se elegerem cuidadoras acrescentaram aos afazeres diários os cuidados relacionados aos esposos idosos, no tratamento do câncer.

\section{Ressignificação da Vida do Cuidador}

A proximidade com o idoso trouxe oportunidades aos familiares/cuidadores de perceberem e valorizarem aspectos positivos, neste período em que a convivência tornou-se muito mais próxima e intensa. Foram expostos como formas de auxiliar no processo de superação das dificuldades e, com isso, evidenciaram novos significados para a vida destas pessoas: maior união, solidariedade, oportunidade de reaproximação, mudanças, reflexões entre as pessoas que participaram deste estudo.

Dos aspectos positivos relatados, a maior união, solidariedade e reaproximação entre o idoso e o cuidador e outros membros da família foram os mais evidentes. Estudos confirmam a união que a doença trouxe entre os familiares, sendo oportunizado aos membros que se solidarizem e que reorganizem seus papéis ${ }^{(14-15)}$. O desempenho do cuidado trouxe a oportunidade de reaproximação entre mãe e filha, superação de conflitos e diferenças anteriormente existentes ${ }^{(1,12)}$.

Em nosso estudo também foi percebida a oportunidade de aproximação, afeto, carinho, não apenas da cuidadora, mas de outros filhos:

[...]hoje, nós nos tornamos mais amigas, sabe? [...] saber entender ela, como ela também saber me entender[...]. (Sara - Entrevista 16/05/2009)

[...] ela tá mais mãe, mais amiga [...] É porque a doença aproxima mais a gente né! (Sara - Entrevista 28/05/2009)

Muito embora percebamos que quantitativamente tenhamos encontrado poucos aspectos considerados como positivos na atividade de cuidar de um idoso com câncer submetido a quimioterapia, é necessário valorizar a representação destes, no contexto familiar de cada idoso e de seu cuidador, o que refletiu em intensas sensações de alegria frente aos resultados alcançados, trazendo assim novos significados para a convivência entre as pessoas e para as próprias cuidadoras.

As dificuldades se apresentaram em maior variedade, foram destacadas: transformações negativas nas relações familiares e sociais ao assumirem o papel de cuidadoras, exigindo abnegação da própria vida, resultando em comprometimento de aspectos físicos, emocionais e sociais.

Para o familiar cuidador, observamos que o adoecimento torna-se muitas vezes um momento de reflexão, quanto à sua situação frente ao ente querido adoecido, bem como quanto à sua própria vida; revelando sentimentos não públicos e aflorando situações latentes.

[...] Tanto ela como eu ... é um alerta pra minha vida também! Trabalhando, sempre correndo, sem ter tempo de olhar pra nós mesmos ... sabe? É o que aconteceu com ela ... acha que envolve só em ...casa, envolve só em cuidar dos outros, e ... da gente mesmo??? (Sara - Entrevista 16/05/2009)

Assumir integralmente o papel de cuidadora, mesmo que realizado com satisfação, gerou mudanças em diferentes áreas da vida; deixar de fazer o que gostava para dedicar-se ao cuidado integral do marido adoecido:

[...] e eu fui lutando, fui ficando só por conta ... Eu larguei o serviço de cuidar de casa [...] O meu tempo é só pra ele! (Ana - Entrevista 07/05/2009)

O isolamento social, caracterizado pelo distanciamento de familiares e amigos, evidenciado pela pequena ou quase nula participação da cuidadora em eventos sociais e momentos de lazer, resulta em sobrecarga emocional, sentimento de solidão, insatisfação gerando prejuízos na sua qualidade de vida ${ }^{(1)}$.

Mudanças nos hábitos alimentares da família também estiveram presentes na vida das cuidadoras:

[...] é fazer uma comida diferente, porque ele não está podendo comer de tudo [...] Ele só estava conseguindo comer sopa [...]. (Jô Entrevista - 26/01/2009)

Eu às vezes passava 3 dias sem comer comida. Eu fazia sopinha, aqueles caldos, pra ele tomar um pouquinho, aí eu tomava aquilo, não fazia comida. Então, ele (Nenê) falava: "Você precisa comer, se eu perder você, como é que eu fico?" (Ana - Entrevista - 07/05/2009)

Além destas, observamos que inicialmente houve falta de conhecimento sobre como lidar com a situação, mesmo quando analisamos a participante que exercia atividade profissional de cuidadora de idosos. Todas se mostraram despreparadas e inseguras e, mediante a falta de recursos e informações acessíveis em domicílio, passaram a buscar ajuda com pessoas leigas: 
[...] olha, o tratamento, também foi uma novidade pra mim, eu nunca tinha entrado num hospital de pacientes com câncer; os sintomas que ela teve ... o que eu tive assim (orientações) foi uma amiga minha que também tava com a mãe terminando de fazer a radio[...]. (Sara - Entrevista 16/05/2009)

Em recente revisão da literatura, os autores comprovam que há falta de conhecimento e preparo para cuidar de idosos em diferentes condições crônicas, o que pode comprometer o cuidado e trazer sobrecarga ao cuidador ${ }^{(16)}$. Foram trazidas ainda outras mudanças na rotina de vida diária. A cuidadora que era recém-casada, anteriormente ao adoecimento de seu pai, vivia apenas para o cuidado de sua casa e de seu marido. A vinda de seu pai para conviver com o casal alterou totalmente sua rotina de esposa cuidadora do lar:

[...] mas tá muita correria mudou muito, não só a minha; a vida dele também né coitado, mas a minha, mudou muuuuito!! (Maria - Entrevista 29/04/2009)

Hãã ... minha vida virou de cabeça pra baixo!! Porque a gente tem uma rotina em casa né, faz tudo sempre nos horários certos ... eu faço tudo ... eu tenho que estar me deslocando com ele né. Eu tô muito cansada! [...] eu não tenho ninguém em casa pra me ajudar, sou eu que faço tudo! (Maria - Entrevista 14/05/2009)

O casal passou a ter conflitos e até mesmo uma convivência distante, o esposo ficava vários dias fora de casa (viajava a trabaIho) e Maria, sem poder tomar partido de qualquer lado, torna-se nervosa, entristecida e mais solitária na função de cuidadora:

Minha mãe briga com ele: "você acha que tá num hotel? ... a Maria é muito boba... faz tudo que você quer[...] (Maria - Entrevista 14/05/2010)

Ai meu marido fala: "você é boba!!! Ele tem que comer o que tem em casa; você não tem que ficar se desdobrando pra fazer as coisas!" [...] eu, eu não falo nada, deixo ele falar sabe? (Maria - Entrevista 14/05/2010)

O exercício do cuidado, muitas vezes solitário, também apareceu como um dos fatores que sobrecarregavam as cuidadoras, sendo necessário que, em muitos momentos, deixassem o seu próprio cuidado para cuidar do outro. Este aspecto foi destacado em estudos em que a carga de atividade dos cuidadores era realizada quase sempre de forma solitária ${ }^{(1,17-18)}$. Com a abnegação de seus costumes e valores, em detrimento da vida dos idosos adoecidos que se encontravam sob os seus cuidados; esta foi, na verdade, as mais perceptíveis transformações na vida das cuidadoras. A observação da condição de cuidador solitário traz indignação para quem cuida, por visualizar os demais membros da família com a liberdade perdida ${ }^{(1)}$.

Outros estudos relatam diferentes sentimentos negativos, que se tornam presentes nos cuidadores de pessoas com qualquer grau de dependência. Em relação à atividade exercida, os mais comuns foram: estresse, sobrecarga, dedicação exclusiva, auto-cobrança; depressão, ansiedade; tensão, conflitos, perdas e frustrações ${ }^{(1,15,17)}$. Encontramos em nossas cuidadoras, todos os sentimentos citados nos estudos, comprovando mais uma vez que a atividade de cuidar de pessoas idosas com câncer submetidas a quimioterapia pode gerar condições de vida negativa. $\mathrm{O}$ cuidador traz para si cargas físicas, emocionais e psicológicas que podem incorrer em prejuízos à sua própria vida, sendo essa uma ressignificação negativa.

As condições sócio-econômicas insuficientes também interferiram no processo:

[...] e ele (Joaquim) não ter convênio ... a minha preocupação era esta: gasto! E eu sabia a dimensão do problema; o gasto, então, eu não, não sabia como é que a gente iria fazer, né! (Maria - Entrevista 29/04/2009)

[...] dificuldade é dinheiro!! Dificuldade pra cuidar é dinheiro. Porque se você não tiver dinheiro é difícil. Porque sempre ele falava pra mim assim: "a gente tem que ter uma economia porque na hora que a gente precisar, na hora duma doença [...] Nós acabamos com o dinheiro de um terreno! (Ana - Entrevista 28/05/2009)

Como se trata de pacientes atendidos pelo SUS e da classe popular, temos um grupo que apresenta maior vulnerabilidade social. Ao considerarmos situações de agravos à saúde, como o câncer, o precário poder financeiro fica comprometido, especialmente se o paciente é o provedor da família.

Ah, dificuldade é dinheiro! Dificuldade pra cuidar é dinheiro. Nós acabamos com o dinheiro! [...] era um tal de ir no sacolão, no supermercado e [...] haja dinheiro, e compra remédio, e compra isso e compra aquilo [...]". (Ana - Entrevista 28/05/2009)

Estudos apontam a dificuldade financeira para o cuidado como uma das principais, podendo gerar angústia no cuidador, que deseja oferecer o melhor para seu idoso ${ }^{(1,16,19-20)}$.

Independentemente das necessidades partirem do cuidador ou do próprio paciente, todo o núcleo familiar sofre certo comprometimento financeiro, exigindo redirecionamento de prioridades, de necessidades pessoais e coletivas, o que normalmente gera sensação de desconforto, insegurança e medo de não serem capaz de oferecer o cuidado necessário, pela falta de recursos. Ressaltamos a escassez de estudos e publicações que trazem propostas de intervenções e estratégias para diminuir a sobrecarga do cuidador do idoso; este fato foi evidenciado em publicação recente ${ }^{(16)}$.

Apesar de todas as dificuldades vivenciadas, sofrimentos, resignação e abnegação, a quimioterápica antineoplásica é vista pelos pacientes e seus familiares/cuidadores como sinônimo de esperança e de nova oportunidade de vida ${ }^{(15)}$.

\section{CONSIDERAÇÕES FINAIS}

Prestar cuidado informal pode trazer sobrecarga ao cuidador e desestruturação da vida, pois, diante do despreparo 
haverá ansiedade, insegurança, auto-cobrança e desgaste, que geram sofrimento. Desta forma, acreditamos que as exigências para exercer o cuidado de uma pessoa idosa adoecida pelo câncer, que está passando pelo tratamento quimioterápico, enfrentando seus efeitos colaterais e reações adversas, são muito maiores do que simplesmente disponibilidade de tempo, ou um carinho. A necessidade de ressignificação da própria vida deve partir do próprio cuidador, mas, deverá contar com a equipe de saúde, oferecendo apoio formal e atuando como facilitadora deste processo, não permitindo que se perpetue a condição de cuidador inseguro, solitário e adoecido pelo cansaço. O envolvimento emocional, as limitações de conhecimento e o desempenho de novos papéis no contexto domiciliar são dificuldades frequentes vivenciadas pelos cuidadores, as quais são traduzidas em sentimento de sobrecarga física, emocional e financeira.

Frente ao exposto e levando-se em consideração o objetivo deste artigo, consideramos que preparar o cuidador para exercer esta atividade no domicílio é papel do enfermeiro visto que, cuidar do idoso fragilizado e de seu cuidador é uma responsabilidade deste profissional. O apoio formal é importante referência para o cuidador e traz consigo o sentimento de confiança. Assim, o enfermeiro atuará como facilitador, pois, reconhece as reações adversas e efeitos colaterais inerentes ao tratamento, bem como o cuidado necessário diante das principais dificuldades encontradas pelos cuidadores. A consulta de enfermagem ao cuidador deve privilegiar informações, esclarecer dúvidas e ajudá-lo a enfrentar as dificuldades com os recursos adequados às suas necessidades sócio-culturais. Reconhecemos que ainda são precários os suportes públicos para o adequado acompanhamento dos idosos e seus cuidadores, mas, com a implantação das políticas e programas de atenção específicos que têm sido planejados, poderão contribuir para a diminuição destas condições e, consequentemente, com a diminuição da sobrecarga.

Mediante a acurada percepção, esta deve mobilizar toda a equipe de saúde para o envolvimento e preparo deste cuidador, buscando assim disponibilizar pessoas capacitadas e seguras para o cuidado de seu paciente em domicilio, de maneira que sejam minimizadas as consequências negativas do processo de cuidar em domicílio, mantendo, sobretudo, a qualidade de vida do paciente e dos cuidadores.

\section{REFERÊECIAS}

1. Vieira MCU, Marcon SS. Significados do processo de adoecer: o que pensam cuidadoras principais de idosos portadores de câncer. Rev Esc Enferm USP [Internet]. 2008 [acesso em 12 de dezembro de 2012];42(4):752-60. Disponível em: http://www.scielo.br/scielo.php?script=sci_artt ext\&pid $=$ S0080-62342008000400019

2. Oliveira AMS, Pedreira LC. Cuidadores de idosos dependentes no domicílio: mudanças nas relações familiares. Rev Bras Enferm [Internet]. 2012 [acesso em 12 de dezembro de 2012];65(5):730-6. Disponível em: http://www.scielo.br/scielo.php?pid=S0034$-71672012000500003 \&$ script $=$ sci_arttext

3. Alvarez AM, Gonçalves LTH. Enfermagem e o cuidado ao idoso no domicílio. Rev Bras Enferm [Internet]. 2012 [acesso em 12 de dezembro de 2012];65(5):715-6. Disponível em: http://www.scielo.br/scielo.php?script=sci_artt ext\&pid = S0034-71672012000500001

4. Anjos ACY. As repercussões do cuidar do idoso em quimioterapia oncológica na vida do familiar cuidador [tese]. Ribeirão Preto (SP): Universidade de São Paulo; 2010.

5. Azevedo GR, Santos VLCG. (Handicapped) caregiver: the social representations of family members about the caregiving process. Rev Latinoam Enferm [Internet]. 2006;14(5):770-80.

6. Simonetti JP, Ferreira JC. Estratégias de coping desenvolvidas por cuidadores de idosos com doença crônica. Rev Esc Enferm USP [Internet]. 2008 [acesso em 12 de dezembro de 2012];42(1):19-25. Disponível em: http://www. scielo.br/pdf/reeusp/v42n1/03.pdf

7. Langdon EJ, Wiik FB. Antropologia da saúde e doença: uma introdução ao conceito de cultura aplicado às ciências da saude. Rev Latinoam Enferm. 2010;18(3):459-66.
8. Caprara A, Landin LP. Etnografia: uso, potencialidades e limites na pesquisa em saúde. Interface Comun Saúde Educ.2008;12(25):363-76.

9. Stake RE. Case studies. In: Denzin NK; Lincoln YS. Strategies of qualitative inquiry. Thousand Oaks (US): Sage Publications; 2003. p.134-64.

10. Carter B, Mc GOLDRICK M. As mudanças no ciclo de vida familiar: uma estrutura para terapia familiar. 2. ed. Veronese MAV, tradutora. Porto Alegre (RS): Artes Médicas; 2001. p. 206-221.

11. Braun V, Clark V. Using thematic analysis in psychology. Qualitative Research Psycology. 2006; 3(2):77-101.

12. Nascimento LC, Moraes ER, Silva JC, Veloso LC, Vale ARMC. Cuidador de idosos: conhecimento disponível na base de dados LILACS. Rev Bras Enferm. 2008;61(4):514-7.

13. Fonseca NR, Penna AFG, Soares MPG. Ser cuidador familiar: um estudo sobre as conseqüências de assumir este papel. Physis (Rio J.). 2008;18(4):727-43.

14. Instituto Brasileiro de Geografia e Estatística (IBGE). Censo Demográfico 2000 - Características gerais da população, religião e pessoas com deficiência [Internet]. [S.I]: IBGE; 2010 [acesso em 12 de dezembro de 2012]. Disponível em: http://www.ibge.gov.br/home/estatistica/populacao/censo2010/caracteristicas_religiao_deficiencia/ default_caracteristicas_religiao_deficiencia.shtm

15. Cecagno S, Souza MD, Jardim VMR. Compreendendo o contexto familiar no processo saúde-doença. Acta Sci Health Sci. 2004;26(1):107-12.

16. Stolagli VP, Evangelista RBM, Camargo OP. Implicações sociais enfrentadas pelas famílias que possuem pacientes com sarcoma ósseo. Acta Ortop Bras. 2008;16(4):242-6. 
17. Oliveira DC, D'Elboux MJ. Estudos nacionais sobre cuidadores familiares de idosos: revisão integrativa. Rev Bras Enferm. 2012;65(5):829-38.

18. Carvalho CSU. A necessária atenção à família do paciente oncológico. Rev Bras Cancerol [Internet]. 2008 [acesso em 12 de dezembro de 2012];54(1):87-96. Disponível em: http://www.inca.gov.br/rbc/n_54/v01/pdf/revisao_7 pag_97a102.pdf
19. Marques AKMC, Landim FLP, Collares PM, Mesquita RB. Apoio social na experiência do familiar cuidador. Ciênc Saúde Coletiva [Internet]. 2008 [acesso em 03 abril de 2010]. Disponível em: http://www.scielo.br/scielo. php?script $=$ sci_arttext $\&$ pid $=$ S1413-81232011000700026

20. Creutzberg M. Tratar mais a pessoa idosa, sobretudo a que está acamada: subsídios para o cuidado domiciliar. Mundo da Saúde. 2000;24(4):298-305. 